\title{
SequencingTasks in Developing an Accredited Social Work Program and Assessing Program Outcomes
}

\author{
Charles Zastrow \\ Tim Reutebuch
}

\begin{abstract}
Two of themajor challenges for developing an accredited social work program areto sequencethetasks in developing an educational program and to develop accurateand useful assessment instruments. A model for sequencing thetasks is presented, and a field placement evaluation instrument is highlighted in assessing the extent to which students areattaining the program objectives. Programs need to utilize multiple measures of program outcomes.
\end{abstract}

Keywords: Accreditation, assessment, program development

T he accreditation standards of EPAS (Educational Policy and Accreditation Standards) (Council on Social work Education, 2003) outline what baccalaureateand master's programs in social work must address in order for a program to develop or reaffirm an accredited social work program. However, EPAS does not present a model for successfully accomplishing the tasks necessary to design an accredited program. Administrative officials and faculty at colleges and universities in the United States who are seeking to develop an accredited social work educational program are often uncertain as to the specific steps that need to be taken. This articlehas two focuses. First, it summarizes an approach, or model, of the sequencing of tasks for developing an educational program. In the summary, it is advantageous to sequence the tasks in the following order: statement of program mission; statement of program goals; statement of program objectives; integrating program objectives with course objectives and into course syllabi; designing an assessment plan and developing assessment instruments; implementing the assessment plan; and using the results of assessment to improve the educational program.

The second focus of the article is to illustrate how a carefully constructed field placement instrument, completed by the agency supervisors in field placement, has immense usefulness in assessing the extent to which students are attaining the program objectives.

Charles Zastrow is Professor and Tim Reutebuch is Assistant Professor, University of WisconsinWhitewater, Whitewater, WI 53190.

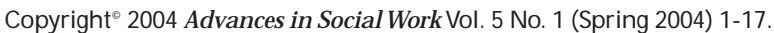

Indiana University School of Social Work. 


\section{SEQUENCING OF TASKS IN DEVELOPING AN ACCREDITED PROGRAM}

For accomplishing complex projects, Hepworth and Larson (1993, p. 398-401) have noted it is essential to first partialize the tasks into "sub-tasks" in order to reduce them to manageable parts. These parts consist of discreteactions that need to be undertaken. After partializing tasks into sub-tasks, the next step is to order the sub-tasks so that they flow from one to another in a natural sequence.

The senior author of this article has visited/consulted with over 50 programs who were in the process of developing a social work program, or were in the process of seeking reaffirmation of accreditation. The senior author has also served two terms on the Commission on Accreditation. With this background experience, a model (or approach) has been formulated as to the sequencing of tasks in developing an accredited social work program.

The faculty at a college or university who are seeking to develop an accredited social work program (in this model) should first state its program mission. The mission should be consistent with the campus' mission and should reflect the intent for such mission statements as specified in Educational Policy and Accreditation Standards (EPAS) (Council on Social Work Education, 2003). To illustrate a program mission, our program has adopted the following mission statement:

"The Baccalaureate Social Work Program (BSW) at the University of Wisconsin-Whitewater seeks to prepare social work students so as to ensue that they obtain the knowledge and skills necessary for beginning generalist social work practice as competent, effective professionals in urban and rural areas. The program has an emphasis on the strengths of client systems. Recognizing that people are an integral part of their environment, the program utilizes an ecological model of human behavior. Another emphasis of the program is on preparing social work professionals who are committed to services to the poor and oppressed, and who are oppressed, and who are committed to promoting social and economic justice for populations-at-risk. The social work program also has a commitment to developing social work knowledge and providing leadership in the development of social work systems."

In our Self-Study documents, we further elaborate on how this program mission statement is consistent with the campus' mission.

Next, program goals need to be stated, which should be derived from the program mission, and also reflect the intent of EPAS. To illustrate, our program has stated its goals as follows:

1. To prepare students for beginning generalist practice who facilitate the functioning of individuals, families, groups, organizations, and communities by helping them to accomplish tasks, and obtain and use resources.

2. To prepare students for beginning generalist practice who engage in prevention activities that promote well-being.

3. To prepare students for beginning generalist practice who participate in the planning, formulation, and implementation of social policies, services, 
resources and programs needed to meet basic human needs and support the development of human capacities.

4. To prepare students for beginning generalist practice who participate in the pursuit of policies, services, resources, and programs through organizational or administrative advocacy and social or political action; to empower groups at risk; and to promote social and economic justice.

5. To prepare students for beginning generalist practice without discrimination, with respect, and with knowledge and skills related to clients' age, class, color, culture, disability, ethnicity, family structure, gender, marital status, national origin, race, religion, sex, and sexual orientation.

6. To prepare students for beginning generalist practice who participate in the development and testing of professional social work knowledge and skills.

7. To prepare students to recognizethe gl obal context of social work practice.

8. To emphasize preparation for providing direct services to diverse populations (with particular attention to populations-at-risk in Southeastern Wisconsin), to alleviate poverty and oppression, and to promote social and economic justice for all its citizens.

9. To providestudents with content about social contexts of social work practice, the changing nature of those contexts, the behavior found in organizations, and the dynamics of change.

10. To provide curricula and teaching practices at the forefront of the new and changing knowledge base of social work and related disciplines.

11. To provide curricula that build on a liberal arts perspective to promote breadth of knowledge, critical thinking, and communication skills.

UW-Whitewater Social Work Self-Study Documents, 2001

In our Self-Study documents, we also elaborate on how these goal statements are consistent with the program mission.

Then, the faculty should state the program objectives, which should relate to the program goals, and also reflect the intent for program objectives as specified in EPAS. The statement of program objectives is very important, as the development of the social work curriculum and assessment plan are largely determined by the statement of these program objectives.

An example of the statement of program objectives follows.

1. Apply critical thinking skills within the context of professional social work practice.

2. Practice within the values and ethics of the social work profession and with an understanding of and respect for the positive value of diversity.

3. Demonstrate the professional use of self.

4. Understand the forms and mechanisms of oppression and discrimination and the strategies of change that advance social and economic justice. 
5. Understand the history of the social work profession and its current structures and issues.

6. Apply the knowledge and skills of generalist social work to practice with systems of all sizes.

7. Apply knowledge of bio-psycho-social variables that affect individual development and behavior, and use theoretical frameworks to understand the interactions among individuals and between individuals and social systems (i.e., families, groups, organizations, and communities).

8. Analyze the impact of social policies on client systems, workers, and agencies.

9. Evaluate research studies and apply findings to practice, and, under supervision, to evaluate their own practice interventions and those of other relevant systems.

10. Use communication skills differentially with a variety of client populations, colleagues, and members of the community.

11. Use supervision appropriate to generalist practice.

12. Function within the structure of organizations and service delivery systems, and under supervision, seek necessary organizational change. (UWWhitewater Social Work Self-Study Documents submitted to the Council on Social Work Education)

Such a statement of program objectives appears to be consistent with the guidelines for such objectives in the Curriculum Policy Statement for Baccalaureate Degree Programs in Social Work Education (Council on Social Work Education, 1994). Such a statement of program objectives also appears to be consistent with the guidelines for such objectives in EPAS (Council on Social Work Education, 2003).

The next step is for faculty to specify the required courses in social work in which material related to these objectives will be taught and assessed. A time-consuming part of this process is to write the syllabi for the required courses. In writing the syllabi, it is important to incorporate (in appropriate courses) the program objectives. Specified content in the syllabi needs to be "relevant to the mission, goals, and objectives of the program and to the purposes, values, and ethics of the social work profession" (Council on Social Work Education (2003, p. 34). The syllabi for the required courses also need to address the following foundation curriculum content, which is described in EPAS: values and ethics; diversity; populations-at-risk and social and economic justice; human behavior and the social environment; social welfare policy and services; social work practice; research; and field education (Council on Social Work Education, 2003, p. 34-36).

It is desirablefor each required social work course syllabus to specify: lecture content, classroom activities, reading material, and assessment measures (such as tests, role-plays, classroom exercises, and student presentations) to assess the extent to which students are attaining the course objectives (which incorporate the program objectives). 
The next step is for the faculty to develop its assessment plan, which utilizes a variety of measurement instruments and procedures. Examples of multiple assessment measures include: periodic alumni surveys, student course evaluations, focus group meetings with selective students (such as minority, nontraditional students) to identify shortcomings in the educational program, passage rates on the certification exam for graduates of the program, and evaluation by agency supervisors on the extent to which interns are attaining program objectives. (A later section in this article will highlight a field placement instrument for assessing the extent to which students in a social work program are attaining the program objectives.)

The next two steps in developing the social work educational program are: (a) implementing the assessment plan, and (b) using the results of the assessment to improve the educational program. These components will also bediscussed later in this article.

\section{THE IMPORTANCE OF ASSESSING PROGRAM OUTCOMES}

The Educational Policy and Accreditation Standards (EPAS) require that accredited baccalaureate and master's programs in social work education in the United States have "an assessment plan and procedures for evaluating the outcome of each program objective" (Council on Social Work Education, 2003, p. 41). EPASfurther states, "The plan specifies the measurement procedures and methods used to evaluate the outcome of each program objective (Council on Social Work Education, 2003, p. 41).

The Organization that oversees accreditation entities in the United States is the Council for Higher Education and Accreditation (CHEA). When accreditation entities apply for accreditation recognition by CHEA, these entities must show their accreditation standards and procedures are consistent with CHEA's principles. Principle 1 of CHEA's Statement on Good Practices and Shared Responsibility in the Creation and Application of Specialized Accreditation Standards states:

(Educational Outcomes) Standards should be designed to produce desired or needed educational outcomes for a profession and should refer to resources only to the extent required for graduates to emergefrom programs intellectually prepared for their professional lives. (Council for Higher Education Accreditation, 2001, p. 1)

This principle emphasizes the importance for all accredited higher education programs to assess the extent to which graduates areattaining program objectives. There are a variety of ways (previously mentioned) in which programs can assess the extent to which students are attaining the program objectives. One of these approaches is developing a field placement instrument in which field instructors assess the extent to which students are attaining program objectives. This approach has a number of strengths. An evaluation instrument can be constructed (relatively easily) that focuses on identifying the extent to which students are attaining program objectives. Since evaluation of intern performance has to be conducted for grading purposes, using the same evaluations to assess program outcomes does not require much additional work. Finally, this approach has the additional advantage of having external observers (field supervisors) evaluate the 
interns. (External observers are apt to be moreobjective than evaluation plans that utilize students or faculty to assess the extent to which students are attaining the program objectives.)

\section{Using a Field Placement Instrument to Assess Program Outcomes}

The Field Placement Instrument used by our program to assess program objectives is presented in the Appendix at the end of this article. The agency supervisors fill out this evaluation at midterm and at the end of placement. In this social work baccalaureate program, practically all of the students enroll in block field placements-they are at an agency for one term (either fall, spring, or summer) for 480 hours-either four or five days a week. The faculty designed this instrument with the goal of using the results to provideinformation on the extent to which students are attaining the 12 program objectives that were previously identified in this article. In developing this instrument, it should be noted that the program faculty concluded that since the 12 program objectives are so broadly stated, the faculty needed to identify a number of more specific items for each program objective, which interns are evaluated upon by agency supervisors.

The program has an annual departmental meeting to review the results of the various outcome measures that are used. At this meeting the identified shortcomings of the program are discussed by the faculty, and curriculum changes are then usually made to address these shortcomings. This process (including the assessment results and the resulting changes in curriculum) are then communicated to the campus administrative officials in an annual report. The faculty also communicate this information to the members of the program's Advisory Board.

\section{The Results from the Field Placement Instrument}

In the past two years, 167 students have had field placement and graduated from the program. The results of the field placement evaluations were tabulated for all the interns who graduated in 2001 and 2002. A variety of mean scores were tabulated. Through deliberation, the faculty decided that mean scores of higher than 2.00 were a matter of concern. Mean scores of 2.00 or lower were considered acceptable by the faculty as they included the two following ratings: "(1) The intern has excelled in this area" and "(2) The intern is functioning above expectations for interns in this area." The following are the results.

The mean scores were tabulated on the midterm evaluations and separately on the final evaluations to get an average mean score of all the items under each program objective. For example, under Objective \# (Applies critical thinking skills within the context of professional social work practice) the average mean score received on the following items (grouped together) was tabulated:

1.1 Has good assessment skills

1.2 Has good problem-solving skills

1.3 Has good data gathering skills

1.4 Analyzes complex material well

1.5 Has good critical thinking capacities 
The average mean scores for each program objective for both the midterm evaluations, and the final evaluations, were less than 2 . This result indicated, overall, that agency supervisors believe that the interns in the program are doing quite well in attaining the program objectives. Furthermore, it was found the average mean scores for each program objective for the final evaluations were more highly rated (that is closer to 1.0) than for the midterm evaluations. This rating suggests the agency supervisors perceive interns, on the average, are attaining the program objectives to a higher extent at the end of field placement than at the middle of field placement.

The mean scores for each item on the final evaluations were then tabulated. All of the mean scores for each item were found to be less than 2.0. This suggests the agency supervisors believe that, on the average, the graduating students in the program have sufficiently attained the knowledge, values, and skills expected of beginning level, generalist social workers.

As far as program development is concerned, probably the most useful results were obtained when the mean scores for each item on the midterm evaluations were tabulated. The following items received mean scores higher than 2.0-indicating they were a matter of concern to agency supervisors.

Item Number:

(Readers will note the wording of these items has been slightly changed for clarity purposes)

\subsection{Assessment skills}

1.2 Problem solvingskills

5.3 Knowledge of community resources

5.4 Resourcefulness in identifying and using resources not commonly known

5.5 Understanding of existing social welfare programs

6.4 Effectiveness in macro change efforts in the community

7.1 Knowledge of biological variables in assessing clients

7.2 Knowledge of psychological variables in assessing clients

7.3 Knowledge of sociological variables in assessing clients

7.6 Integrating information from appropriate assessment tools

7.7 Knowledge of intervention theories and techniques

9.3 Capacity to evaluate his or her own practice interventions

9.4 Capacity to evaluate the services provided by the field placement agency

10.1 Being assertive

10.7 Written work

10.9 Contributing his or her thoughts in group meetings 


\section{Using the Assessment Results to Improve the Educational Program}

It appeared to the faculty that agency supervisors were indicating by these midterm evaluation results that these are the areas that interns (on average) have some deficiencies in the first few weeks of placement.

The faculty met at its annual assessment meeting and reviewed the results. For a few of the items, such as "Knowledge of community resources" and "Resourcefulness in identifying and using resources not commonly known," it was thought that a contributing factor to such items being identified was that a number of interns selected a field placement in a geographic area in which they were not familiar. Nevertheless, it was thought that faculty supervisors should giveguidance to interns in these areas in field seminar meetings and in the faculty supervisor's weekly review of intern logs.

After considerable discussion, it was agreed that faculty who teach social work majors in any course should (in the future) refer those students having difficulties in the following areas: writing skills, being assertive, speaking in classes, assessment skills, problem solving skills, knowledge of intervention theories and techniques, and evaluation skills, to the Department's Standards and Support Committee.

The Standards and Support Committee was formed several years ago to work with students identified as having issues involving academic or professional performance. The main thrust is to develop an individualized plan to assist each referred student in improving the identified academic or professional performance areas. For example, a student who is nonassertive and says little in class is apt to be urged to enroll in the department's one-credit assertiveness course. A student who has deficiencies in writing skills is apt to be urged to take an additional writing course and go to the university's writing laboratory for assistance in writing all of his/ her papers. As a last resort, if a student does not show improvement in an essential social work competence area, the Standards and Support Committee has the authority (with appropriate due process and grievance procedures) to terminate a student's future enrollment in the social work program.

The program will continue to use the field placement evaluation instrument, along with other assessment instruments and procedures, to assess the extent to which students are attaining the identified program objectives.

\section{SUMMARY}

This article has two main focuses, which are interrelated. First, it presents an approach (or model) of the sequencing of tasks for developing an accredited social work educational program. Thesuggested sequencing of tasks includes: specifying a mission statement; specifying program goals; specifying program objectives; integrating program objectives with course objectives and into course syllabi; designing an assessment plan and developing assessment instruments, implementing the assessment plan; and using the assessment results to improve the educational program. It is anticipated that this model, or approach, will be particularly useful to those programs that are in Candidacy and those programs that are in the process of preparing their self-study documents for reaffirmation of accreditation. 
The second focus of this article demonstrates that a carefully constructed field placement instrument, completed by agency supervisors in field placement, has considerable usefulness in assessing the extent to which students (right before graduation) are attaining the program objectives. (It should be noted that social work programs need to use multiple measures of the extent to which students are attaining program objectives.) Finally, social work programs need to use multiple measures of the extent to which students are attaining program objectives.

\section{References}

Council for Higher Education Accreditation. (2001, September). "Statement on Good Practices and Shared Responsibility in the Creation and Application of Specialized Accreditation Standards," Washington, D.C.: Author.

Council on Social Work Education. (1994). Handbook of Accreditation Standards and Procedures, $4^{\text {th }}$ edition, Alexandria, VA: Author.

Council on Social Work Education. (2003). Handbook of Accreditation Standards and Procedures, $5^{\text {th }}$ edition, Alexandria, VA: Author.

Hepworth, D.A., \& J. Larsen. (1993). Direct Social Work Practice, $4^{\text {th }}$ ed. Pacific Grove, CA: Brooks/Cole Publishing.

UW-Whitewater Social Work Self-Study Documents, submitted to the Council on Social Work Education. (2001).

\section{Additional Resource References}

Baskind, F.R., Shank, B.W., \& Ferraro, E.K. (2001). Accountability for professional practice: Assessment in social work education. In C.A. Palomba \& T.W. Banta (Eds.), Assessing student competence in accredited disciplines: Pioneering approaches to assessment in higher education (pp. 95-119). Sterling, VA: Stylus.

Cuzzi, L.C., Holden, G., Chernack, P., Rutter, S., \& Rosenberg, G. (1997). Evaluating social work field instruction: Rotations versus year-long placements. Research on Social Work Practice, 7, 402-414.

Cuzzi, L.C., Holden, G., Rutter, S., Rosenberg, G., \& Chernack, P. (1996). A pilot study of fieldwork rotations vs. year long placements for social work students in a public hospital. Social Work in Health Care, 24, 7391.

Gambrill, E.D. (2000). Honest brokering of knowledge and ignorance. Journal of Social Work Education, 36, 387-397.

Gambrill, E.D. (2002). Evaluating the outcomes of social work practice: A pilot program. Journal of Social Work Education, 38, 355-362.

Garcia, J.A., \& Floyd, C.E. (2002). Addressing evaluative standards related to program assessment: How do we respond? Journal of Social Work Education, 38, 369-382.

Holden, G., Barker, K., Meenaghan, T., \& Rosenberg, G. (1999). Research self-efficacy: A new possibility for educational outcomes assessment. Journal of Social Work Education, 35, 463-476.

Holden, G., Meenaghan, T., Anastas, J., \& Metrey, G. (2002). Outcomes of social work education: The case for social work self-efficacy. Journal of Social Work Education, 38, 115-133.

Hull, G.H., Mather, J.H., Christopherson, P.M., \&Young, C.M. (1994). Quality assurance in social work education: A comparison of outcome assessments across the continuum. Journal of Social Work Education, 30, 388-396.

Lubinescu, E.S., Ratcliff, J.L., \& Gaffney, M.A. (2001). Two continuums collide: Accreditation and assessment. New Directions for Higher Education, 113, 5-21.

Sheridan, M. (1998). Assessment of the 1992 Curriculum Policy Statement. Council on Social Work Education: Alexandria, VA. 
Sheridan, M. (1999, Winter). COEP Assessment of 1992 Curriculum Policy Statement complete. Social Work Education Reporter, 47, pp. 7, 28.

\section{Author's Note:}

Address correspondence to: Charles Zastrow, Social Work Department, University of WisconsinWhitewater, Whitewater, WI 53190, USA. E-mail: chzastrow@charter.net 


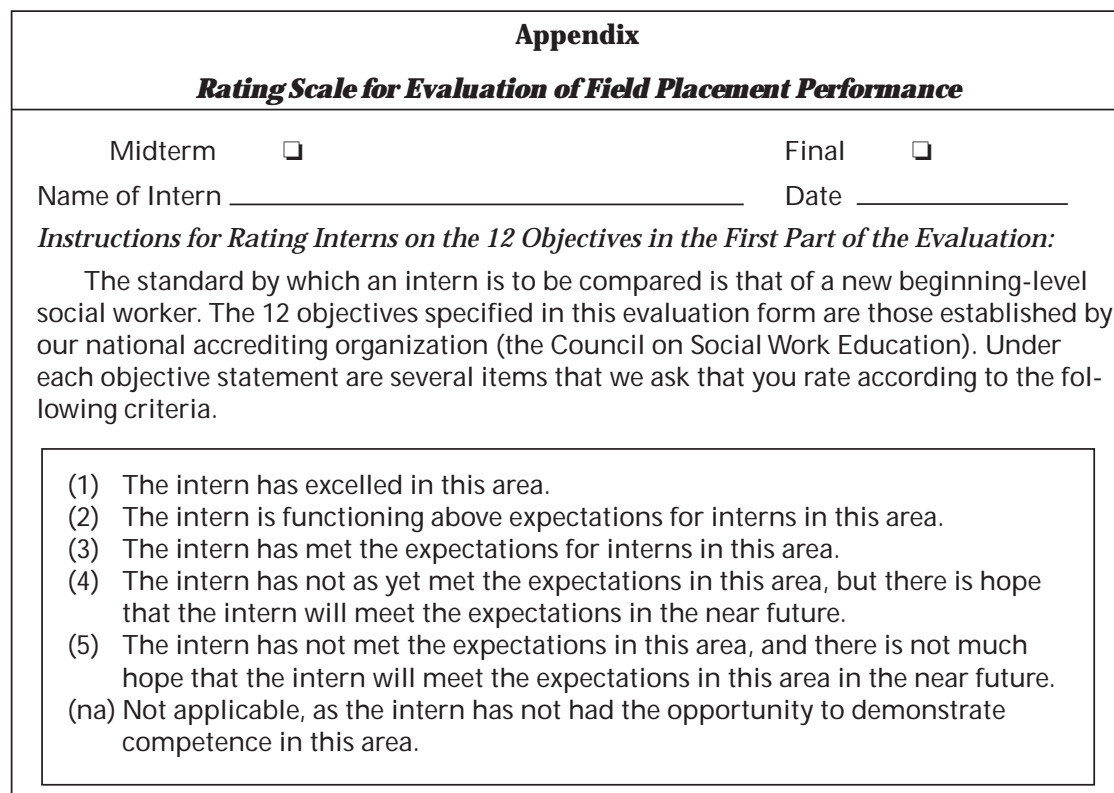

Comments may be made under any objective, if desired. Please be sure to indicate those areas in which you think the intern is particularly strong and those areas that need improvement.

This evaluation is intended to give the intern feedback about her or his performance. The agency supervisor's rating of these items will not directly be used to calculate the grade that is given to the intern. The faculty supervisor has the responsibility of assigning the grade for the course. The grade that is assigned will be based on: the faculty supervisor's overall evaluation of the student's performance in placement in conjunction with the agency supervisor's evaluation (65\%); intern logs (10\%); seminar participation ( $5 \%)$; two papers ( $10 \%$ each-20\% total).

If you prefer to use another evaluation system in addition to this form to evaluate a student's performance, please discuss this with the faculty supervisor.

\section{Objective \#1: Applies critical thinking skills within the context of professional} social work practice.

1.1 Has good assessment skills

1.2 Has good problem-solving skills

1.3 Has good data gathering skills

1.4 Analyzes complex material well

1.5 Has good critical thinking capacities
12345 na

$12345 \mathrm{na}$

12345 na

12345 na

12345 na

\section{Comments:}




\section{Objective \#2: Practices within the values and ethics of the social work profession and with an understanding of and respect for the positive value of diversity.}

2.1 Has a commitment to promoting the well-being of clients

12345 na

2.2 Respects the right of clients to self-determination

$12345 \mathrm{na}$

2.3 Is perceptive and attentive to cultural diversity

12345 na

2.4 Follows agency's guidelines on confidentiality

2.5 Has the capacity to communicate well with a variety of diverse groups

12345 na

2.6 Treats all clients with dignity, courtesy, and fairness

12345 na Comments:

\section{Objective \#3: Demonstrates the professional use of self.}

3.1 Presents self as a professional social worker

12345 na

3.2 Has a high level of self awareness

12345 na

3.3 Dress and appearance are consistent with agency standards

12345 na

3.4 Is self-confident

12345 na

3.5 Maintains poise and control in stressful situations

12345 na

3.6 Conveys an interest in helping others

$12345 \mathrm{na}$

3.7 Has good interviewing skills

12345 na

3.8 Formulates realistic contracts with clients (including goals and planned intervention) and follows through, as appropriate to the agency setting

$12345 \mathrm{na}$

3.9 Has ability to utilize group dynamics therapeutically

12345 na

3.10 Has ability to observe a group and make accurate assessments

12345 na

3.11 Has ability to co-facilitate or facilitate a group effectively

12345 na

Comments: 
Rating Scal e for Evaluation of Field Placement Performance (cont.)

Objective \#4: Understands the forms and mechanisms of oppression and discrimination and the strategies of change that advance social and economic justice.

4.1 Treats diverse clients with dignity and respect

12345 na

4.2 Has considerable awareness of the forms and mechanisms of oppression and discrimination

$12345 \mathrm{na}$

4.3 Is committed to advancing social and economic justice for individuals and groups who are subjected to discrimination

4.4 Uses pertinent information to assess clients, including attending to cultural/ethnic influences, gender roles, diversity of lifestyle, and access to resources

4.5 Has an understanding of the impacts of various environmental conditions on individuals, groups, families, and communities (such as poverty and discrimination)

12345 na Comments:

\section{Objective \#5: Understands the history of the social work profession and its cur- rent structures and issues.}

5.1 Is knowledgeable about the agency's mission-its history, goals, and functions in the community

12345 na

5.2 Is knowledgeable about current social problems

12345 na

5.3 Is knowledgeable about community resources

12345 na

5.4 Demonstrates resourcefulness in identifying and using resources not commonly known

12345 na

5.5 Has a good understanding of existing social welfare programs

12345 na

Objective \#6: Applies the knowledge and skills of generalist social work to practice with systems of all sizes.

\section{Comments:}

6.1 Is effective in providing services to individuals

12345 na

6.2 Is effective in providing services to groups

12345 na

6.3 Is effective in providing services to families

12345 na

6.4 Is effective in macro change efforts in the community (macro change efforts include efforts to develop new services and to improve existing services)

12345 na

6.5 Has the skills and tact to effectively work toward organizational changes in agencies Comments: 
Rating Scale for Evaluation of Field Placement Performance (cont.)

Objective \#7: Applies knowledge of bio-psycho-social variables that affect individual development and behavior, and uses theoretical frameworks to understand the interactions among individuals and social systems (i.e., families, groups, organizations, and communities).

7.1 Effectively uses knowledge of biological variables in assessing

12345 na clients

7.2 Effectively uses knowledge of psychological variables in

12345 na assessing clients

7.3 Effectively uses knowledge of sociological variables in

12345 na assessing clients

7.4 Is knowledgeable about social system theory

12345 na

7.5 Is effective in using the agency's assessment system

12345 na

7.6 Uses and integrates information from appropriate

12345 na assessment tools

7.7 Has a good knowledge of intervention theories and

12345 na techniques

7.8 Demonstrates ability to establish intervention plans, and through in implementing the plans

12345 na

Comments:

Objective \#8: Analyzes the impact of social policies on client systems, workers, and agencies.

8.1 Is knowledgeable of the field placement agency and its

12345 na organizational structure

8.2 Is knowledgeable of the relationship between the field

12345 na placement agency and the larger human service delivery system in the community

8.3 Has the ability to see gaps in the service delivery system and has the ability to suggest appropriate plans for change

8.4 Understands the community and makes use of that understanding in working with clients

$12345 \mathrm{na}$

8.5 Has an understanding of how social policy issues impact clients and the field placement agency

8.6 Understands the limitations of the field placement agency in regard to financial and material resources and in regard to agency policy, and is able to work effectively within these constraints

12345 na

12345 na

Comments: 
Rating Scale for Evaluation of Field Placement Performance (cont.)

Objective \#9: Evaluates research studies and applies findings to practice, and, under supervision, evaluates his or her own practice interventions and those of other relevant systems.

9.1 Has demonstrated an appreciation of the importance of research

12345 na

9.2 Is interested in reading the results of research studies that are relevant to improving services at this field placement

12345 na agency

9.3 Has the capacity to evaluate his or her own practice interventions

12345 na

9.4 Has the capacity to evaluate the services provided by this field placement agency

9.5 Has demonstrated competence in research at this field placement

9.6 Has demonstrated competence in adhering to the documentation and records requirements of the agency

Comments:

Objective \#10: Uses communication skills differentially with a variety of client populations, colleagues, and members of the community.

10.1 Is assertive

12345 na

10.2 Written work communicates ideas clearly

12345 na

10.3 Has written work completed on time

12345 na

10.4 Has written work completed in an efficient and accurate manner

12345 na

10.5 Is able to pull out the most important material/information to incorporate in his/ her written work

10.6 Is familiar with and clearly understands the style of writing utilized within the agency (i.e., knows the language, anachronisms, abbreviations, etc.) and makes appropriate use of these in assessments and other written work

10.7 Written work reflects a clear understanding of the social worker's role within the agency and service delivery system

10.8 Has good public speaking skills

12345 na

12345 na

10.9 Willingly contributes his or her thoughts and opinions in group meetings

10.10 Appropriately adjusts his or her choice of work in communicating with different populations (e.g., communicates well with such diverse populations as children, adolescents, and other professionals) 


\begin{tabular}{|c|c|c|}
\hline \multicolumn{3}{|c|}{ Rating Scale for Evaluation of Field Placement Performance (cont.) } \\
\hline \multicolumn{3}{|c|}{ Objective \#11: Uses supervision appropriate to generalist practice. } \\
\hline 11.1 & Is prepared for supervisory conferences & 12345 na \\
\hline 11.2 & Has a positive attitude toward supervision & 12345 na \\
\hline 11.3 & Is receptive to suggestions & 12345 na \\
\hline 11.4 & Is open to new ideas and differing points of view & 12345 na \\
\hline 11.5 & $\begin{array}{l}\text { Seeks supervision when needed, and asks appropriate } \\
\text { questions }\end{array}$ & 12345 na \\
\hline 11.6 & Appropriately informs supervisor of problematic situations & 12345 na \\
\hline 11.7 & $\begin{array}{l}\text { Follows through effectively on work responsibilities } \\
\text { assigned by supervisor(s) }\end{array}$ & 12345 na \\
\hline 11.8 & $\begin{array}{l}\text { Handles differences of opinion with supervisor(s) with } \\
\text { tact and diplomacy }\end{array}$ & 12345 na \\
\hline \multicolumn{3}{|c|}{ Comments: } \\
\hline \multicolumn{3}{|c|}{$\begin{array}{l}\text { Objective \#12: Functions well within the structure of organizations and service } \\
\text { delivery systems, and under supervision, seeks necessary organizational change. }\end{array}$} \\
\hline 12.1 & Good attendance and punctuality & 12345 na \\
\hline 12.2 & Promptness in completing work assignments & 12345 na \\
\hline 12.3 & Good at prioritizing the work that needs to be done & 12345 na \\
\hline 12.4 & Dependable & 12345 na \\
\hline 12.5 & Is a team player & 12345 na \\
\hline 12.6 & Is a self-starter & 12345 na \\
\hline 12.7 & Has good professional relationships with clients & 12345 na \\
\hline 12.8 & $\begin{array}{l}\text { Has a commitment to continue to seek out opportunities } \\
\text { for professional growth }\end{array}$ & $12345 \mathrm{na}$ \\
\hline 12.9 & Is aware of personal limitations & 12345 na \\
\hline 12.10 & Has good time management skills & 12345 na \\
\hline 12.11 & Abides by agency's policies and standards & 12345 na \\
\hline $\begin{array}{l}12.12 \\
\text { Comm }\end{array}$ & $\begin{array}{l}\text { Is professional in making suggestions for changes } \\
\text { lents: }\end{array}$ & 12345 na \\
\hline
\end{tabular}


Rating Scale for Evaluation of Field Placement Performance (cont.)

\section{Overall Evaluation at MIDTERM:}

Please check one of the following at the midterm evaluation. At the final evaluation do NOT complete this section.

This intern is excelling in field placement by performing above expectations for interns.

This intern is meeting the expectations of a field placement intern.

This intern is functioning somewhat below the expectations of a field placement intern. There is a question whether this intern will be ready for beginning level social work practice by the end of placement.

This intern is functioning below the expectations of a field placement intern. There is considerable concern that this intern will not be ready for beginning level social work practice by the end of placement. This intern should perhaps be encouraged to pursue another major.

Comments/elaboration:

\section{FINAL OVERALL EVALUATION:}

Please check one of the following at the final evaluation. At the midterm evaluation do NOT complete this section.

This intern has excelled in field placement by performing above expectations for interns. If an appropriate position were open at this agency for a beginning level social worker, this intern would be considered among the top candidates for this position.

This intern has met the expectations of the field placement. This intern is ready for beginning level social work practice.

This intern is not yet ready for beginning level social work practice.

This intern is not yet ready for beginning level social work practice and has demonstrated serious problems in performance, and perhaps should be encouraged to pursue another major.

\section{Comments/elaboration:}

Signature of Agency Field Instructor

Agency Date

The following section should be completed by theintern:

My agency supervisor and faculty supervisor have discussed this evaluation with me, and I have received a copy. My agreement or disagreement follows:

Intern's Signature

Date

\section{I agree with the evaluation \\ I do not agree with evaluation}

If the intern disagrees with the evaluation she/ he should state that disagreement in writing and submit a copy to both the agency supervisor and the faculty supervisor. The dis agreement should be specific and should also relate to the items in the evaluation. 